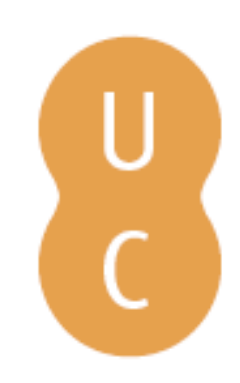

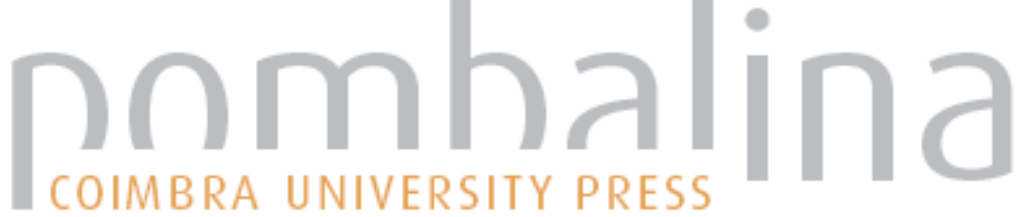

\section{Licenciamento ambiental de extrações de areia e argila no estado de São Paulo,} Brasil

Reis, F. A. G. V.; Giordano, L. do C.; Medeiros, G. A. de; Cerri, L. E. da Autor(es): $\quad$ S.; Zaine, J. E.; Mascaro, S. de A.; Pilachevsky, T.; Macedo, J. G. C. de; Amendola, D. de P.; Domingues, L. S. V.; Christianini, A. L. C.; Andrade, C. M.; Lumiatti, G.; Lunardi, M. $\begin{array}{ll}\text { Publicado por: } & \text { Centro de Estudos Clássicos e Humanísticos da Universidade de } \\ \text { Coimbra }\end{array}$

URL persistente:

DOI:

URI:http://hdl.handle.net/10316.2/31492

DOI:http://dx.doi.org/10.14195/978-989-26-0531-9_47

Accessed : $\quad$ 26-Apr-2023 00:35:40

A navegação consulta e descarregamento dos títulos inseridos nas Bibliotecas Digitais UC Digitalis, UC Pombalina e UC Impactum, pressupõem a aceitação plena e sem reservas dos Termos e Condições de Uso destas Bibliotecas Digitais, disponíveis em https://digitalis.uc.pt/pt-pt/termos.

Conforme exposto nos referidos Termos e Condições de Uso, o descarregamento de títulos de acesso restrito requer uma licença válida de autorização devendo o utilizador aceder ao(s) documento(s) a partir de um endereço de IP da instituição detentora da supramencionada licença.

Ao utilizador é apenas permitido o descarregamento para uso pessoal, pelo que o emprego do(s) título(s) descarregado(s) para outro fim, designadamente comercial, carece de autorização do respetivo autor ou editor da obra.

Na medida em que todas as obras da UC Digitalis se encontram protegidas pelo Código do Direito de Autor e Direitos Conexos e demais legislação aplicável, toda a cópia, parcial ou total, deste documento, nos casos em que é legalmente admitida, deverá conter ou fazer-se acompanhar por este aviso.

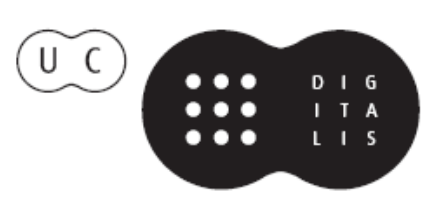





\title{
LICENCIAMENTO AMBIENTAL DE EXTRAÇÓES DE AREIA E ARGILA NO ESTADO DE SÁO PAULO, BRASIL
}

\author{
ENVIRONMENTAL LICENSING FOR EXTRACTION OF SAND \\ AND CLAY IN THE SAO PAULO STATE, BRAZIL
}

F. A. G. V. Reis ${ }^{1}$, L. do C. Giordano ${ }^{1}$, G. A. de Medeiros ${ }^{1}$, L. E. da S. Cerri ${ }^{1}$, J. E. Zaine ${ }^{1}$, S. de A. Mascaro ${ }^{1}$, T. Pilachevsky ${ }^{1}$, J. G. C. de Macedo ${ }^{1}$, D. de P. Amendola ${ }^{1}$, L. S. V. Domingues ${ }^{1}$, A. L. C. Christianini ${ }^{1}$, C. M. Andrade' ${ }^{1}$, G. Lumiatti ${ }^{1} \&$ M. Lunardi $^{1}$

Resumo - O licenciamento ambiental no Brasil é o instrumento de gestáo ambiental mais difundido e aplicado, principalmente, por ser um requisito legal para o planejamento, instalação, operação, ampliação e desativação de empreendimentos e atividades potencialmente poluidoras. Nesse contexto, o licenciamento de extraçóes de areia para construçáo civil e argila para produção de cerâmica vermelha apresentam várias legislaçóes que tratam do tema, envolvendo diferentes órgáos públicos que precisam ser consultados. Essas extraçōes são, na maioria dos casos, desenvolvidas por micro, pequenos e médios empreendimentos, mas que são fundamentais para o desenvolvimento da construçấo civil do país, atuando localmente nas proximidades dos centros urbanos. O presente artigo tem como objetivo analisar os procedimentos para licenciamento ambiental de extraçóes de areia e argila no estado. Pela análise realizada pode-se verificar que existe uma diversidade grande de legislaçóes, somente considerando os requisitos legais da Secretaria de Meio Ambiente do Estado, além da necessidade de solicitar em pelo menos 4 órgáos públicos diferentes de nível federal, estadual e municipal, autorizaçôes específicas até a emissão da licença de operação. Essa situação dificulta o entendimento do processo, principalmente, no que refere-se a classificação do porte do empreendimento e quais projetos serão exigidos, tornando problemático o planejamento e até da viabilidade econômica, especialmente, de pequenos empreendimentos.

Palavras-chave - extração de areia e argila, licenciamento ambiental, procedimentos

\footnotetext{
${ }^{1}$ Universidade Estadual Paulista Júlio de Mesquita Filho - UNESP - Rio Claro; e-mail: fabioreis@ rc.unesp.br
} 
Abstract - The environmental licensing in Brazil is the most widely applied environmental management tool because it is a legal requirement for the planning, installation, operation, expansion and deactivation of potentially polluting developments and activities. In this context, the licensing of extraction of sand for construction and clay for red ceramic production showed various laws dealing with the issue, involving different government agencies that need to be consulted. These extractions are, in most cases, developed by micro, small and medium companies, but are fundamental to the development of the construction of the country, acting locally in the vicinity of urban centers. This article aims to analyze the environmental licensing procedures for extraction of sand and clay in the state. For the analysis can be seen that there is a large diversity of laws, only considering the legal requirements of the Environment Secretariat of the State, besides the need to request at least four different government agencies at federal, state and municipal specific authorizations until the issuance of operating license. This situation complicates the understanding of the process, especially as relates to the classification of the enterprise and which projects will be required, making it problematic to planning and economic viability, especially for small companies.

Keywords - extraction of sand and clay, environmental licensing, procedures

\section{1 - Introdução}

O licenciamento ambiental é um dos principais instrumentos de gestão ambiental, sendo na realidade o que inicialmente qualquer tipo de empreendimento necessita por em prática para regularizar suas atividades a legislação. Na grande maioria dos países é necessário realizar licenciamento de um empreendimento ou atividade que seja potencialmente causadora de impacto. Atualmente, até micros e pequenos empreendimentos tem que se adequar as condições mínimas ambientais, necessitando realizar algum tipo de licenciamento, mesmo que simplificado.

No Brasil, o Conselho Nacional de Meio Ambiente (CONAMA) é o órgão que regulamenta em nível federal os procedimentos para licenciamento ambiental de empreendimentos e atividades potencialmente poluidoras. Contudo, a maior parte das licenças ambientais é emitida por órgãos estaduais, existindo, nesse contexto, uma série de legislaçôes e normas estaduais para o licenciamento dependendo do tipo, porte e localização do empreendimento ou atividade.

Em complemento, os municípios também estabelecem requisitos legais para o licenciamento, especialmente, relacionados as diretrizes de uso e ocupação do solo em seu território. Existindo, portanto, uma quantidade considerável de legislaçôes, normas técnicas, procedimentos administrativos e órgáos para licenciamento ambiental, o que acaba dificultando e encarecendo a implantação e operação de novas empresas e confundido empresários e até os próprios técnicos.

A extração mineral foi no país um dos primeiros ramos econômicos a terem de se adequar aos padróes ambientais, principalmente, pelo seu potencial de degradação, historicamente reconhecido.

Em termos ambientais, REIS et al (2005) destaca que o licenciamento de atividades minerárias, tem como objetivo diminuir os impactos causados ao meio ambiente por esses processos minerários, exigindo uma série de documentos e projetos, para que 
sejam propostas e implantadas medidas mitigadoras, de controle e/ou compensatórias, de modo que o impacto causado por essas mineraçóes seja o menor possível. Entretanto, na maior parte dos casos para se efetivar o licenciamento de uma extração é necessário cumprir requisitos, procedimentos e etapas em 5 ou 6 órgáos diferentes.

Nesse contexto, as extraçóes de areia para uso da construçáo civil e argila para produção de cerâmica vermelha, devido suas características de localização, em geral, nas proximidades de centros urbanos e pela predominância de micro, pequenos e médios empreendimentos (REIS et a.l, 2005; CABRAL JUNIOR et al., 2010), passou no Estado de São Paulo por uma série de alteraçôes na legislação. Como exemplo, somente na Secretaria de Meio Ambiente do Estado de São Paulo existem as seguintes Resoluçóes SMA que envolvem as extraçôes de areia e argila:

- Resolução SMA n. 51/06: disciplina o licenciamento ambiental das atividades minerárias no Estado de São Paulo, integrando os procedimentos dos órgãos públicos responsáveis;

- Resolução SMA 54/04 - Dispóe sobre procedimentos para o licenciamento ambiental no âmbito da Secretaria do Meio Ambiente;

- Resolução SMA n. 69/97: dispóe sobre a extração de areia e argila vermelha na Bacia Hidrográfica do rio Jaguari Mirim;

- Resolução SMA n. 42/96: disciplina o licenciamento ambiental dos empreendimentos minerários de extração de areia na Bacia Hidrográfica do Rio Paraíba do Sul; e,

- Resolução SMA n. 42/94 - dispóe sobre os procedimentos para análise de EIA/ RIMA.

Ressalta-se, ainda, as Resoluçôes SMA n. 18/89, 26/93, 4/99 e 47/06, que já foram revogadas. Isso sem considerar os requisitos legais locais e regionais que muitas vezes envolvem outras questôes.

Atualmente, mesmo após a unificação de procedimentos, uma extração mineral de areia e argila, mesmo um micro empreendimento necessita conseguir autorizaçóes no mínimo em 4 órgãos diferentes, que são: Departamento Nacional de Produção Mineral (DNPM), Prefeitura Municipal (em algumas prefeituras são necessárias autorizaçôes de 2 órgãos municipais diferentes), Companhia Ambiental do Estado de São Paulo (CETESB) e Departamento de Águas e Energia Elétrica (DAEE), o que contribui, em muitos casos, em um período superior a 3 anos para um micro ou pequeno empreendimento conseguir todas as autorizaçôes para sua operação.

Nesse contexto, o presente artigo tem como objetivo analisar e discutir o licenciamento ambiental no Estado de São Paulo para extraçôes de areia para construção civil e argila para produção de cerâmica vermelha.

\section{Procedimentos e aspectos legais do licenciamento ambiental}

Para entendimento do processo de licenciamento ambiental no Estado de São Paulo é importante compreender conceitos apresentados na Tabela 1 .

Atualmente, no Estado de São Paulo existem três formas básicas para licenciamento ambiental de extraçôes de areia e argila, para uso na construção civil e produçáo de cerâmica vermelha. 
Tabela 1: Termos e respectivos conceitos usados no licenciamento ambiental no Estado de São Paulo.

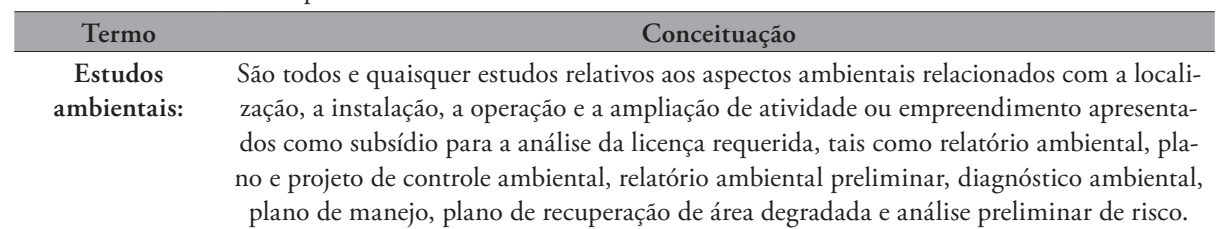

Consulta Prévia: Requerimento encaminhado à SMA solicitando orientação quanto à definição do tipo de estudo ambiental adequado para análise da viabilidade ambiental de atividade ou empreendimento potencial ou efetivamente causador de impacto ao meio ambiente, acompanhado de informaçôes que caracterizem seu porte, sua localização e os impactos esperados para sua implantação.

Estudo Ambien- Documento técnico com informaçōes que permitem analisar e avaliar as consequências tal Simplificado ambientais de atividades e empreendimentos considerados de impactos ambientais (EAS): muito pequenos e não significativos.

Relatório

Ambiental PreliEstudos técnicos e científicos elaborados por equipe multidisciplinar que, além de minar (RAP): atividade, destinam-se a avaliar sistematicamente as consequências das atividades ou empreendimentos considerados potencial ou efetivamente causadores de degradação do meio ambiente, em que são propostas medidas mitigadoras com vistas à sua implantação.

Plano de Compilação e o diagnóstico simplificados de todas as variáveis que o empreendedor Trabalho (PT) entenda como significativas na avaliação da viabilidade ambiental, com vistas à implantação de atividade ou empreendimento, e que servirão de suporte para a definição do Termo de Referência (TR) do Estudo de Impacto Ambiental e do Relatório de Impacto Ambiental (EIA/RIMA).

Termo de Documento elaborado pela SMA/DAIA que estabelece os elementos mínimos necesReferência (TR): sários a serem abordados na elaboração de um EIA/RIMA, tendo como base o Plano de Trabalho, bem como as diversas manifestaçóes apresentadas por representantes da sociedade civil organizada.

Estudo de Im- Estudos técnicos e científicos elaborados por equipe multidisciplinar que, além de pacto Ambiental oferecer instrumentos para a análise da viabilidade ambiental do empreendimento ou (EIA): $\quad$ atividade, destinam-se a avaliar sistematicamente as consequências consideradas efetiva ou potencialmente causadoras de significativa degradação do meio ambiente e a propor medidas mitigadoras e/ou compensatórias com vistas à sua implantaçáo.

Relatório de Im- Documento-síntese dos resultados obtidos com a análise dos estudos técnicos e cientípacto Ambiental ficos de avaliaçáo de impacto ambiental que compóem o EIA, em linguagem objetiva (RIMA): e acessível à comunidade em geral. O RIMA deverá refletir as conclusôes desse estudo com linguagem clara, de modo que se possam entender precisamente as possíveis consequências ambientais do empreendimento ou atividade e suas alternativas e também comparar suas vantagens e desvantagens.

\begin{tabular}{|c|c|}
\hline $\begin{array}{l}\text { Memorial de } \\
\text { Caracterizaçáo } \\
\text { do Empreendi- } \\
\text { mento (MCE) }\end{array}$ & $\begin{array}{l}\text { Documentação técnica que dever ser preenchida em programa específico disponibi- } \\
\text { lizado no site da CETESB, onde são apresentadas as seguintes informaçóes: tipo de } \\
\text { atividade a ser desenvolvida e de licença solicitada; dados básicos de identificação do } \\
\text { empreendimento, empreendedor e o local (informaçóes cadastrais); matéria prima a ser } \\
\text { usada no empreendimento ou atividade; produtos que serão gerados; relaçáo de máqui- } \\
\text { nas e equipamentos; resíduos gerados; e fontes de poluição da água. }\end{array}$ \\
\hline $\begin{array}{l}\text { Memorial de } \\
\text { Caracterizaçáo } \\
\text { do Empreendi- } \\
\text { mento (MCE) } \\
\text { - Adicional de } \\
\text { Mineraçáo }\end{array}$ & $\begin{array}{l}\text { Documentação técnica complementar ao MCE, preenchida em formulário padronizado } \\
\text { da CETESB, no qual são descritas as seguintes informaçóes: identificação do empre- } \\
\text { endedor; histórico da atividade e uso e ocupação do solo; informaçốes gerais sobre o } \\
\text { bem mineral e título minerário; informaçôes sobre as intervençôes ambientais que serão } \\
\text { realizadas; método de extração; práticas de controle da erosão; informaçóes sobre solo } \\
\text { orgânico e estéril; fontes de poluição do ar, ruído e vibração, com as respectivas medidas } \\
\text { de controle; informaçóes sobre a lavra e recuperaçấo ambiental. }\end{array}$ \\
\hline
\end{tabular}

Fonte: Resolução SMA n. 54/04 
No caso de micro empreendimentos minerários foi promulgada a Decisão de Diretoria da CETESB n. 011/2010/P, de 10 de janeiro de 2010, a qual estabelece um licenciamento simplificado para este tipo de empreendimento, que foi definido como aquele empreendimento que possui área requerida e outorgada pelo Departamento Nacional de Produção Mineral (DNPM), menor ou igual a 5 ha, e utilize método de extraçáo manual ou outro método, desde que em pequena escala. $\mathrm{O}$ método de desmonte mecânico pode ser ou não realizado com o auxílio de maquinário, como o caso de retroescavadeira.

Segundo a própria CETESB (2010), as atividades de micro empreendimentos "geralmente é realizada por grupos familiares, que extraem minério de sua própria propriedade, usualmente localizada em área rural", sendo que toda ou boa parte da renda da família provém apenas dessa atividade. São denominados de argileiros ou oleiros, possuindo em muitos casos pequena olaria no mesmo local ou vendem argila para olarias da região.

No caso de extração em leito de rio o licenciamento somente poderá ser realizado mediante iniciativa de lideranças locais (Prefeituras, Associaçóes ou Cooperativas), que deverão providenciar toda a documentação e medidas técnicas necessárias para a regularização da atividade.

Segundo a Decisão de Diretoria n. 011/2010/P, para enquadrar a extração de outros bens minerais (além da argila para fabricação de cerâmica vermelha) e outros métodos de extração (além do desmonte mecânico) como micro empreendimento minerário, deverão ser observados o seguinte critério: a vida útil mínima da jazida, aprovada no DNPM, deverá ser de 20 anos, sendo que poderá ser aceito prazo da vida útil até $10 \%$ menor do que o estabelecido. Nesse caso, o licenciamento desse método de extração será realizado em nome do detentor do título minerário (pessoa jurídica). A extração poderá ser realizada por diversas pessoas, usualmente são membros da mesma família.

A documentação técnica a ser apresentada nesse caso é o Memorial de Caracterização do Empreendimento (MCE) Adicional de Mineração, com planta em escala 1:2.000, com as seguintes informaçôes: poligonal outorgada pelo DNPM, com a demarcação da área de lavra; módulo a serem lavrados a cada período de três anos; localizaçáo da área armazenamento de rejeito; localização da área de armazenamento do rejeito; cotas iniciais e finais; curvas de nível; direção do avanço da lavra; uso e ocupação do solo no entorno imediato do empreendimento; módulos a serem recuperados concomitante com a lavra; identificação das áreas de preservação permanente de nascentes, cursos d'água e topos de morro, se houver; demarcação da área de vegetação a ser suprimida, se couber; demarcação da área da reserva legal (se o imóvel for rural);

Já para mineraçóes de pequeno e médio portes, há a Resolução SMA n. 51, de 12 de dezembro de 2006, da Secretaria de Meio Ambiente do Estado de Sáo Paulo, que estabelece, em seu artigo 6, o licenciamento ambiental por meio da elaboraçáo de Relatório de Controle Ambiental (RCA) e Plano de Controle Ambiental (PCA), desde que o projeto esteja simultaneamente enquadrado nas seguintes situaçóes:

I. A área de extração, conforme planta de detalhe de configuração final (de acordo com roteiro colocado à disposiçáo pela SMA/CETESB) autenticada pelo DNPM e em acordo com o Plano de Aproveitamento Econômico ou Plano de Lavra, seja de até 20 ha, exceto para água mineral;

II. O volume total de material a ser extraído, incluindo minério e estéril, seja até $5.000 .000 \mathrm{~m}^{3}$ (in situ), exceto para água mineral; 
III. A implantação do empreendimento implique supressão de vegetação nativa em área de até 5 ha; nos casos de vegetação de mata atlântica, esse limite aplica-se somente para a vegetação classificada como pioneira ou em estágio inicial de regeneração;

IV. A implantação e o desenvolvimento da atividade não impliquem intervenção em nascentes ou cursos d'água que contribuam diretamente para corpos d'água utilizados em sistemas de abastecimento público;

V. A área a licenciar, conforme disposto no inciso I deste Artigo, não esteja inserida em Zona de Amortecimento de Unidades de Conservação de Proteçáo Integral, nos termos da Lei Federal no 9985/00;

VI. Quando não se tratar de extração de rochas carbonáticas em regióes com evidências de fenômenos cársticos (lista exemplificativa de tipos de rochas e municípios com essa ocorrência no Anexo I).

$\$ 1^{\circ}$ - Mesmo estando simultaneamente enquadrada nas situaçóes descritas no Artigo $6^{\circ}$, a solicitação de licença ambiental será remetida ao Departamento de Avaliação de Impacto Ambiental - DAIA, para consulta, caso haja dúvida quanto à existência ou não de indícios de impacto ambiental significativo no desenvolvimento da atividade minerária, a critério da CETESB ou do DEPRN.

$\$ 2^{\circ}$ - Também serão protocoladas na CETESB as solicitaçóes de licença ambiental de empreendimentos situados em áreas onde existir zoneamento minerário, nos termos definidos no Artigo $2^{\circ}$ da Resolução SMA n. 3, de 22 de janeiro de 99.

Quando o empreendimento não se enquadrar nas diretrizes descritas anteriormente, o empreendedor deverá protocolar consulta para manifestação da CETESB, por meio do Departamento de Avaliação de Impacto Ambiental (DAIA), sobre a necessidade de apresentação de Relatório Ambiental Preliminar (RAP) ou de Estudo de Impacto Ambiental e Relatório de Impacto Ambiental (EIA/RIMA) ou, ainda, atestar a ausência de significativo impacto.

Outra forma de se realizar o licenciamento ambiental no Estado de São Paulo de extraçóes de areia e argila é seguindo as diretrizes das Resoluçóes SMA n. 42/94 e 54/04, que estabelece três situações:

- Empreendimentos ou atividades considerados de impacto ambiental muito pequeno e náo significativo: o licenciamento será realizado por meio do protocolo na CETESB do EAS;

- Empreendimentos ou atividades considerados potencialmente causadores de degradação do meio ambiente: o licenciamento se iniciará com a protocolização na CETESB do RAP, que deverá ser elaborado considerando Termo de Referência Geral para Extraçóes Minerais; e,

- Empreendimentos ou atividades considerados como efetivamente causadores de significativa degradação do meio ambiente: o licenciamento será realizado pela elaboração de EIA/RIMA, iniciando-se pela protocolização de Plano de Trabalho para emissão da CETESB de Termo de Referência Específico para o empreendimento em questão. Destaca-se que para EIA/RIMA é obrigatória a realização de audiência pública.

A tabela 2 apresenta uma síntese dos procedimentos de licenciamento ambiental para extraçôes de areia e argila no Estado de São Paulo. Conforme pode-se observar, não há 
uma única legislação que normatize o licenciamento ambiental para extraçóes de areia e argila, o que leva a dificuldades de interpretação.

Na Resolução SMA n. 54/04 não há clareza como é feita a classificação do porte do empreendimento e, dessa forma, o tipo de documentação e projeto que serão exigidos, isso dificulta a definiçáo de um planejamento por parte dos empreendedores e técnicos para estabelecer custos e tempo do licenciamento.

Nessa situação a definição da classificação do empreendimento é feita por decisão técnica interna do órgão ambiental, no caso a CETESB, o que pode ser modificada mais facilmente e sem a devida participação da sociedade civil.

\section{3 - Licenciamento em regiôes com legislaçôes específicas}

No Estado de São Paulo além das legislaçôes analisadas anteriormente, existem regiôes que possuem normativos específicos devido a alta concentração de mineraçóes, como é o caso da Resolução SMA n. 42, de 16 de setembro de 1996, que disciplina o licenciamento ambiental dos empreendimentos minerários de extração de areia na Bacia Hidrográfica do Rio Paraíba do Sul, e da Resoluçâo SMA n. 69, de 06 de novembro de 1997, que dispóe sobre a extração de areia e argila vermelha na Bacia Hidrográfica do rio Jaguari Mirim.

O objetivo dessas resoluçóes foi de disciplinar as atividades nessas bacias que apresentam uma intensa atividade mineral ao longo das planícies aluvionares, seja em cava como no leito.

A Resolução SMA n. 42/1996 estabeleceu que o licenciamento ambiental das extraçôes de areia na Bacia Hidrográfica do Rio Paraíba do Sul ficou condicionada as áreas consideradas aptas pelo zoneamento minerário elaborado pela Secretaria de Meio Ambiente do Estado, estabelecendo critérios técnicos específicos para extração em cava submersa, dragagem em leito e desmonte hidráulico. No caso da Resolução SMA n. 69/1997 são estabelecidas regras para extraçóes de areia e argila vermelha em cava e leito de rio.

Analisando essas duas resoluçóes específicas pode-se constatar que existem diferenças entre os critérios técnicos exigidos para determinadas situaçôes, como é o caso da distância entre as cavas e a divisa da propriedade (também denominada de faixa lindeira) que no caso da Resoluçấo SMA n. 42/1996 estabelece 25 metros e na Resolução SMA n. 67/1997 define 50 metros. A Resolução SMA n. 42/1996 estabelece, ainda, uma distância mínima de 10 metros entre a borda da cava e a mata, e a Resoluçápo SMA n. 67/1997 define distância mínima de 10 metros entre a borda e das Áreas de Preservação Permanente e dos meandros abandonados.

Portanto, pode-se observar que não existem critérios uniformes para diferentes bacias hidrográficas. A normatização é um aspecto positivo no licenciamento, mas quando é acompanhada de critérios uniformes e justificados tecnicamente. Por exemplo, em relação à faixa lindeira de 50 metros usada para a Bacia do Rio Jaguari Mirim, quais foram os critérios técnicos usados para definir essa distância? E por que na Bacia do Rio Paraíba do Sul essa faixa foi estabelecida em 25 metros? Essa faixa lindeira de 50 metros tem inviabilizado alguns empreendimentos na Bacia do Rio Jaguari Mirim, principalmente, os micro e pequenos empreendimentos, desenvolvido em pequenas propriedades. 
Tabela 2. Síntese das diretrizes de licenciamento ambiental no Estado de São Paulo.

\begin{tabular}{|c|c|c|c|}
\hline $\begin{array}{l}\text { Legislação / } \\
\text { Normatizaçáo }\end{array}$ & $\begin{array}{c}\text { Porte de } \\
\text { Empreendimento }\end{array}$ & Critérios para Enquadramento & Projeto \\
\hline $\begin{array}{l}\text { Decisáo de } \\
\text { Diretoria } \\
\text { CETESB n. } \\
011 / 2010 / P\end{array}$ & $\begin{array}{l}\text { Micro Empreendi- } \\
\text { mentos Minerários }\end{array}$ & $\begin{array}{l}\text { 1) Área requerida e outorgada pelo DNPM: } \\
\text { Menor ou igual a } 5 \text { ha; } \\
\text { 2) Método de extração: Manual ou outro méto- } \\
\text { do, desde que em pequena escala. }\end{array}$ & $\begin{array}{l}\text { MCE Adicional } \\
\text { de Mineração e } \\
\text { Planta 1:2.000 }\end{array}$ \\
\hline $\begin{array}{l}\text { Resoluçáo } \\
\text { SMA n. } \\
51 / 2006\end{array}$ & $\begin{array}{c}\text { Pequenos e Médio } \\
\text { Portes }\end{array}$ & $\begin{array}{l}\text { 1) A área de extração de até } 20 \text { ha, exceto para } \\
\text { água mineral; } \\
\text { 2) O volume total de material a ser extraído, } \\
\text { incluindo minério e estéril de até } 5.000 .000 \mathrm{~m}^{3} \\
\text { (in situ), exceto para água mineral; } \\
\text { 3) Supressão de vegetação nativa em área } \\
\text { de até } 5 \text { ha; nos casos de vegetaçáo de mata } \\
\text { atlântica, esse limite aplica-se somente para } \\
\text { a vegetaçâo pioneira ou em estágio inicial de } \\
\text { regeneração; } \\
\text { 4) Não ocorra intervenção em nascentes ou } \\
\text { cursos d'água que contribuam diretamente para } \\
\text { corpos d'água utilizados em sistemas de abasteci- } \\
\text { mento público; } \\
\text { 5) A área a licenciar não esteja inserida em Zona } \\
\text { de Amortecimento de Unidades de Conservação } \\
\text { de Proteção Integral; } \\
\text { 6) Quando não se tratar de extração de rochas } \\
\text { carbonáticas em regiōes com evidências de fenô- } \\
\text { menos cársticos. }\end{array}$ & RCA e PCA \\
\hline \multirow{3}{*}{$\begin{array}{c}\text { Resoluçóes } \\
\text { SMA n. } 42 / 94 \\
\text { e } 54 / 04\end{array}$} & $\begin{array}{l}\text { Considerados de } \\
\text { impacto ambiental } \\
\text { muito pequeno e } \\
\text { não significativo } \\
\end{array}$ & \multirow{3}{*}{$\begin{array}{l}\text { Não define critérios específicos para classifi- } \\
\text { car o empreendimento conforme seu impacto } \\
\text { ambiental. } \\
\text { A partir da análise do EAS, a SMA define se o } \\
\text { empreendimento será licenciado com o EAS, } \\
\text { RAP ou EIA/RIMA. } \\
\text { Se não houver clareza na classificação do empre- } \\
\text { endimento o empreendedor deve protocolar na } \\
\text { SMA consulta prévia, por meio da apresentação } \\
\text { de Plano de Trabalho para emissão do Termo de } \\
\text { Referência Específico }\end{array}$} & EAS \\
\hline & $\begin{array}{c}\text { Considerados poten- } \\
\text { cialmente causadores } \\
\text { de degradação do } \\
\text { meio ambiente }\end{array}$ & & RAP \\
\hline & $\begin{array}{c}\text { Considerados } \\
\text { como efetivamente } \\
\text { causadores de signi- } \\
\text { ficativa degradação } \\
\text { do meio ambiente }\end{array}$ & & EIA/RIMA \\
\hline
\end{tabular}

\section{4 - Conclusões e considerações finais}

Pela análise dos procedimentos e exigências técnicas para licenciamento ambiental de extraçóes de areia e argila no Estado de Sáo Paulo pode-se concluir que existem muitos requisitos legais que não estabelecem de forma clara o tipo de projeto a ser exigido, principalmente, em relação à Resolução SMA n. 54/04 que remete a decisão à SMA após consulta prévia, o que dificulta o planejamento dos empreendimentos, tanto em termos de custos como de prazos para elaboração dos estudos técnicos e obtenção das licenças. 
A Resolução SMA n. 51/06 é mais específica, determinando critérios bem claros para licenciamento por meio de RCA/PCA. Contudo, a mesma remete para a Resoluçáo SMA n. 54/04 em casos de dúvidas, deixando ao empreendedor a escolha por qual legislação irá licenciar o empreendimento. Essa situação pode gerar problemas de interpretação jurídica. Adicionalmente, existem as legislaçóes específicas para as Bacias do Rio Paraíba do Sul e do Rio Jaguari Mirim que estabelecem outros critérios mais específicos para o licenciamento, gerando outros problemas, tanto por parte dos empreendedores como também dos técnicos.

Ressalta-se que as análises realizadas nesse artigo estáo se baseando somente nas Resoluçôes SMA, não se esquecendo de que existem ainda as legislaçóes federais e municipais e as resoluçôes e deliberações de outros órgãos, tais como DNPM e DAEE.

Portanto, seria recomendável para simplificar o licenciamento, que todos os orgãos envolvidos direta ou indiretamente, juntamente com os técnicos e mineradores, se reunissem para estabelecer uma única legislação, com critérios claros para classificação do porte do empreendimento, a sequência de procedimentos, os tipos de projetos e documentação exigidos em cada caso e a real unificação do licenciamento nos órgãos estaduais.

\section{Referências Bibliográficas}

CABRAL JUNIOR, M.; SUSLICK, S. B.; SUZIGAN, W. (2010) - Caracterização dos arranjos produtivos locais de base mineral no Estado de São Paulo: subsídio à mineração paulista. Revista Geociências, v. 29, n. 1, p. 81-104.

CETESB. (2010) - Companhia Ambiental do Estado de São Paulo. Decisão de Diretoria n. 011/2010/P, de 10 janeiro de 2010. Disponível em: http://licenciamento.cetesb.sp.gov.br. Acesso em: 15 de fev. 2012.

REIS, F.A.G.V.; FRANCO, A.C.M.; PERES, C.R.; BRONZEL, D.; RAFAELA, E.; PONTES, F.F.F. de; GUIZARD, J.; RAFALDINI, M.E.; GIORDANO, L. do . (2005) - Diagnóstico ambiental em minerações de areia e argila no rio Jaguari Mirim, município de São João da Boa Vista (SP). Espírito Santo do Pinhal: Revista Engenharia Ambiental: pesquisa e tecnologia. 2005, v.2, n.1, p. 115-134 